\title{
Deletion of the RNLS Gene using CRISPR/Cas9 as Pancreatic Cell $\beta$ Protection against Autoimmune and ER Stress for Type 1 Diabetes Mellitus
}

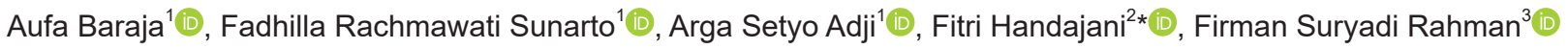 \\ ${ }^{1}$ Faculty of Medicine, Hang Tuah University, Surabaya, Indonesia; ${ }^{2}$ Department of Biochemistry, Faculty of Medicine, Hang \\ Tuah University, Surabaya, Indonesia; ${ }^{3}$ Department of Public Health, Faculty of Public Health, Universitas Airlangga, Surabaya, \\ Indonesia
}

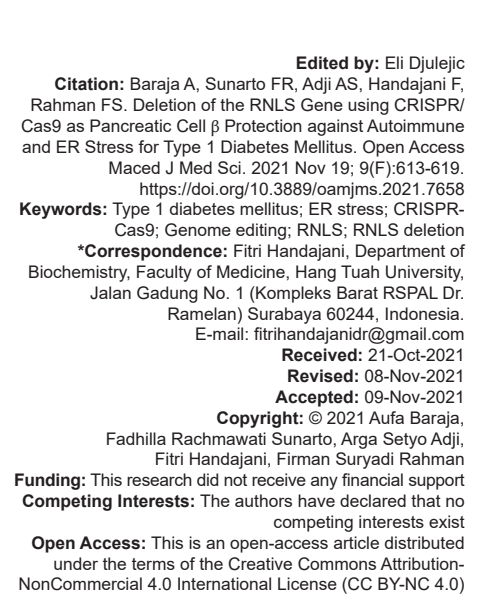

Introduction

Type-1 diabetes mellitus (T1DM) is a chronic disease characterized by impaired insulin production due to damage to pancreatic islet cells, either by autoimmune or idiopathic processes, resulting in T1DM sufferers being unable to produce insulin, so it is known as insulin-dependent diabetes mellitus. Several risk factors cause T1DM, including genetic, environmental, obesity, birth weight, and some ethnic differences [1], [2], [3], [4], [5].

World epidemiological data in 2017 recorded 425 million people having diabetes, which is predicted to grow to over 600 million by 2045 [6]. Based on data from the Indonesian Pediatrician Association (IDAI), there were 1220 T1DM patients in Indonesia until 2018. In 2015 and 2016, there were $63 \%$ of children with T1 diabetes were first diagnosed with Diabetic Ketoacidosis, where this percentage increased to $71 \%$ in 2017 [7].

T1DM is divided into 2 types, namely, type $1 \mathrm{~A}$ diabetes mellitus caused by damage to pancreatic cells due to an autoimmune reaction (more than $95 \%$ of cases), while type $1 \mathrm{~B}$ diabetes mellitus is a b cell damage that is not caused by autoimmune $(<5 \%$ of cases), but due to idiopathic causes. In general, the various types of T1DM can lead to complications such as acute and chronic disorders of macrovascular and microvascular. If there is a long-term disturbance effect on the disease, it can lead to a more progressive diabetes disease followed by complications such as retinopathy, nephropathy, neuropathy at the risk of developing diabetic foot ulcers, and other disorders. Many factors can trigger the occurrence of T1DM. In terms of genetic factors, it is currently known that gene damage occurs at more than 40 gene loci; while environmental factors are related to viral infection and diet [2], [7], [8].

Until now, exogenous insulin therapy is still the main therapy for patients suffering from T1DM. This insulin therapy is usually given by several injections every day [9], [10]. An appropriate daily insulin regimen is also required to achieve optimal glycemic control [11]. In addition to therapy, regulation of adequate physical 
activity and exercise is also important for people suffering from T1DM [7]. However, the lack of patient compliance in exercising and undergoing insulin therapy often becomes an obstacle in the treatment of T1DM [10], [12].

With the development of technology in recent years, many studies have focused on how to influence immune attacks on cells in T1DM. Starting from rituximab, teplizumab, otelixizumab, abatacept, to combination therapy of Antithymocyte Globulin (ATG) Plus G-CSF. Unfortunately, this therapy only delays the initial occurrence of T1DM [9], [11], [13], [14].

Treatment trials using stem cells such as Autologous Non-myeloablative Hematopoietic Stem Cell Transplantation using cyclophosphamide, granulocyte colony-stimulating factor, and rabbit ATG; autologous ex vivo expanded polyclonal Tregs; and Autologous Hematopoietic Stem Cell is also less effective because only temporary [9], [15].

Preventive therapy performed using TRIGR, BABY DIET, and FINDIA also showed no difference [16].

In this case, one solution that can be offered to treat patients suffering from T1DM is gene therapy. Nucleases are the primary too tool in gene therapy. This modern therapy was done by injecting genetic material into the patient's cells to replace the damaged gene or to insert therapeutic transgenes. The idea in implementing gene therapy is to add normal genes to the genome that is mutated or damaged so that these genes can function properly. This therapy provides the theoretical advantage that a single treatment will achieve lasting clinical benefits. Lately, clinical gene therapy test has proven therapeutic benefits and exceptional security. Furthermore, gene therapy has been widely used to treat cancer, cardiovascular disease, infections, decreased metabolic function, lymphatic diseases, radiation-induced injuries, and post-surgical therapy. Gene therapy can also be a solution to treat diabetes mellitus, although the efficacy and safety of this therapy is still a problem [17], [18], [19].

Therefore, there has been no effective therapy to treat DMT. Therefore, through this literature review, the researchers aimed to explore the potential of gene therapy as a therapy that has a permanent effect on T1DM patients.

\section{Methods}

In this study, the articles were searched through PubMed, Google Scholar, Science Direct, Cochrane, and the American Diabetes Association to filter by filtering the past 5 years' study published to obtain actual results as well as by the official guidelines from IDAI. If no or fewer references were found from the past 5 years, researchers would broaden the search by filtering up to the past 10 years. Article searches were performed using keywords T1DM, ER stress, Clustered Regular interspersed Short Palindromic RepeatsCRISPR-related (CRISPR-Cas9), genome editing, Renalase (RNLS), and RNLS deletion.

Meanwhile, article screening was done by adjusting the title and abstract to the research topic. When the title and abstract matched, it was then preceded by checking the availability of the article in full-text. Eventually, the researcher then read the entire article to determine whether the article is useful and appropriate to the topic.

\section{Results and Discussion}

\section{T1DM}

T1DM is divided into several types, those are type $1 \mathrm{~A}$ caused by autoimmune and type $1 \mathrm{~B}$ (idiopathic) caused by non-autoimmune, which is also caused by secondary diseases such as pancreatitis. The occurrence of T1DM is characterized by a loss of B cell mass of about $80-90 \%$, causing clinical symptoms such as hyperglycemia. It is known that $10-30 \%$ of patients suffering from T1DM have relatives who also have the same disease. This is probably caused by a genetic predisposition related to the major histocompatibility complex (MHC). In this case, MHC involves HLA Class II alleles known as HLA-DQ and HLA-DR. The increase in risk factors for T1DM is also caused by mutations involving genes inside or outside the MHC [2], [5].

The occurrence of T1DM starts from the pancreatic cells, those are cell $\alpha$ and cell $\beta$. Insulin produced by cell $\beta$ has the function of influencing the body's cells so that they can use glucose as energy. The hormones secreted by the pancreatic cells are formed to balance blood glucose levels, in which when the blood glucose level is low, then the pancreas cells will produce glucagon and vice versa. Insulin and glucagon have opposite work in regulating and maintaining the balance of blood glucose levels. T1DM patients experience other autoimmune disorders, such as celiac disease and thyroid disorders.

T1DM is divided into three stages, 2 of them are subclinical and 1 is a late-stage with symptoms. Stage 1 in T1DM is known as the subclinical stage where 2 or more antibodies are present (IAA, IA-2A, or $\mathrm{ZnT8A}$ ). At this stage, the blood glucose level is normal (normoglycemia). Then, at Stage 2, blood glucose levels become abnormal (dysglycemia) due to the death of cells $\beta$. In Stage 3 which is the clinical stage, the occurrence of cell $\beta$ death results in insulin deficiency, abnormal blood glucose levels, and the occurrence of hyperglycemia symptoms [2], [5]. 


\section{Endoplasmic reticulum (ER) in T1DM}

Many studies found that the ER can be targeted to prevent the death of cell $\beta$ on T1DM. Like other secretory cells, pancreatic cell $\beta$ island contains more ER than non-secretory cells, so they are more susceptible to ER stress due to their physiological function, namely insulin biosynthesis. As a cell organelle, ER has several functions, including; protein folding of newly synthesized secretory proteins, calcium storage, and pro-apoptotic and anti-apoptotic signallers [20], [21], [22].

A balance between protein load and ER folding capacity is required to maintain the quality of insulin synthesized. To maintain this balance, the RE has a quality control called the unfolded protein response (UPR). The imbalance between the protein that must be folded and the folding capacity of the ER results in a large number of misfolded proteins. The misfolded protein will accumulate in the lumen of the ER which then causes ER stress and leads to the activation of the UPR. In physiological conditions, the main function of the UPR is to restore homeostasis RE by decreasing the RE stress, improving insulin production, and preventing the death of cell $\beta$. However, in certain pathological conditions and continuous occurrence of UPR activation will cause a malfunction in RE function to the death of cell $\beta$. UPR deficiency can also lead to the death of cell $\beta$ and T1DM [20], [21], [23].

As ER protector, UPR has three protein agents that act as stress sensors when quality control is not up to standard. These three agents comprise protein kinase $R$ - like ER kinase (PERK), inositol requiring enzyme $1 \mathrm{a}$, and activating transcription factor 6 (ATF6). These three sensors are usually kept in an inactive state by binding to the chaperone binding immunoglobulin protein (BiP). Active BiP increases protein folding, inserts polypeptides, and removes misfolded proteins leading to endoplasmic-reticulum-associated protein degradation. When misfolded proteins accumulate in the lumen of the ER, BiP separates from PERK, IRE1, and ATF6 which is then activated. IRE1 and PERK can switch from monomeric inactive conformations to oligomers allowing autophosphorylation and activation. Meanwhile, ATF6 is cleaved into an active form and enters the nucleus to increase the transcription of genes that respond to ER stress [23], [24].

Environment and genetics are also assumed as factors that can induce ER stress in cell $\beta$. This is indicated by the increase in free fatty acids, cytokines, viral infections, and the occurrence of hyperglycemia which can cause ER stress and eventually lead to diabetes. The ability of cell $\beta$ in treating the ER stress may be the cause of some individuals being prone to ER stress [20].

ER stress can also be caused by ER calcium depletion which is caused by hyperglycemia, free fatty acids, cytokines, and thapsigargin (TG). ER calcium depletion occurs when cytosolic calcium increases in the ER. The leak of ER calcium into the cytosol causes an increase in post-translational modification (PTM) in cells $\beta$. PTM protein may cause loss of immune tolerance because it is seen as a neoantigen in the immune system. Once an antibody is against cell PTM $\beta$, this will lead to the deployment of an antigen that led to the various positivity of patient antibodies and eventually leads to the death of cell $\beta$ and the T1DM [20].

In several studies conducted on mice, genetic knockout/deletion of the PERK, IRE1, Elf2a, and ATF6 genes showed the role of physiological and pathological responses. Although PERK KO mice were able to survive, they had growth defects such as pancreatic dysfunction, skeletal dysplasia, and hyperglycemia because they could not maintain the integrity of the ER [23], [24].

In studies conducted in humans, mutation on PERK gene causes Wolcott-Rallison syndrome which is indicated by permanent neonatal diabetes and epiphyseal dysplasia. Wolfram Syndrome gene mutations whose function is to regulate transmembrane proteins to reduce ER stress are also related to T1DM [23].

PERK has a dichotomous role, in which it can distinguish the severity of ER stress and promote growth stop to allow repair if possible or apoptosis when ER stress is severe. Elf2 is the main target of PERK. Once activated, Elf2 stops the protein synthesis, allowing cells to overcome the excessive misfolded, and restoring the ER homeostasis. However, in prolonged ER stress response, PERK/Elf2 induces cell death through the factor of C/EBP Homologous Protein CHOP transcription [24].

The effects of a lack of IRE1/XBP1, PERK, and ATF6 give different responses in different environments. Under the conditions of glucose deficiency, PERK will encourage the formation of respiratory super complexes in the mitochondria as alternative energy. In contrast, on low-glucose exposure to CD4 T cells in the tumor environment under ER stress, mitochondrial respiration is reduced. Therefore, it can be found that RE stress regulates the onset, progression, and severity of a wide range of pathological diseases such as diabetes, cancer, and obesity [24].

\section{Genes associated with type-1 diabetes}

Genetic factors are one of the causes of T1DM. It has been identified by Genome-wide association studies (GWAS) that dozens of genes influence T1DM. GWAS also reported the relationship between T1DM and the viral RNA receptor gene region, thus finding IFIH-1 as the first gene for suspected T1DM. In addition, GWAS identified multiple gene loci using meta-analytical studies combined with population studies. There were 50 gene loci associated with T1DM including PTPN22, RGS1, CD55, AFF3, IFIH1, 
STAT4, CTLA4, CCR5, interleukin (IL)-2, HLA-DQB1, TNFAIP3, TAGAP, SKAP2, I KZF1, GLIS3, IL2RA, PRKCQ, ZMIZ1, RNLS, INS, CD69, CYP27B1, ERBB3, SH2B3, GPR183, DLK1, RASGRP1, CTSH, CLEC16A, IL27, GSDMB, ORMDL3, PTPN2, CD226, TYK2, PRKD2, FUT2, SIRPG, UBASH32, AIRE, TLRQ7, TLR8, GAB3, HLA-B, HLA-DRB1, HLA-C BACH2, and IL-10 [25], [26]. Another previous study has also identified genes associated with T1DM. The study was conducted by providing NIT-1 cell transduction (cell $\beta$ derived from non-obese diabetic [NOD] mice who develop insulinoma) with lentiviral rat genome-scale CRISPR knockout (Gecko)-A collection consisting of 60,000 guide RNA (gRNA) targeting approximately 19,050 genes. The use of a low multiplicity of infection was also done so that most cells only carry one mutation. After 8 weeks of giving the implant of NIT-1 cells into immunodeficiency NOD-side mice and injection of splenocytes from diabetic NOD mice that murders $b$ cells, there were only 11 gRNA that survived from the autoimmune response. One of these genes is RNLS, a candidate gene in the human genome associated with T1DM risk [27].

\section{Potential for the deletion of RNLS in T1DM}

RNLS is a newly discovered flavoprotein that is strongly expressed in the kidney and heart with the functions of metabolizing the catecholamines in the kidney [28], [29]. In addition, RNLS functions regulate blood pressure and cardiovascular function [30].

Based on the results of the study, the deletion of RNLS in mice may exacerbate cerulein-induced pancreatitis. This was proven by the provision of recombinant RNLS that can reduce the severity of pancreatitis. RNLS also has anti-inflammatory effects, so it can protect against tissue damage from pancreatitis. Therefore, RNLS deficiency may increase the risk of pancreatitis [31].

In the liver, RNLS can reduce the risk of fatty liver disease (FLD). The provision of exogenous RNLS is also useful for protecting the liver from ischemia/ reperfusion (IR) injury by reducing oxidative stress, improving mitochondrial function, reducing apoptosis in liver tissue, and increasing the hepatocyte defense when experiencing oxidative stress. Therefore RNLS deficiency can cause susceptibility to FLD and IR injury [32].

A study also shows that RNLS deficiency is associated with hypertension. The study proved that the deletion of RNLS can increase the pulse rate and blood pressure in mice. On the other hand, another research that was conducted in Swedish urban communities claimed that there was no evidence of an association between the RNLS gene and hypertension or other cardiovascular diseases [33].

Other studies further stated that the deletion of RNLS only occurs on cell $\beta$ which will be transplanted to protect these cells from autoimmune reactions. This study was carried out by injecting splenocytes from diabetic NOD mice (Figure 1). As a result, the cell $\beta$ with RNLS mutations may survive for only 2 months compared to cells b plain that only last 1-2 weeks. Cell- $\beta$ may survive due to RNLS mutations, in which the immune recognition of the mutation of cells $b$ is disturbed. Such mutations cause the weak response of T polyclonal $\beta$-cell-reactive CD8+ in diabetic NOD mice. However, the RNLS mutation did not affect the response of all-rejection, so that the mutation of cell $\beta$ is still destroyed by the response of allogenic. Thus, it can be concluded that RNLS mutations in cells are not immune to immune detection, but only resistant to autoreactive stimulation of T CD8+ cells. The deletion of RNLS also does not interfere with the differentiation of stem cells into cell $\beta$ and does not affect insulin secretion [27].

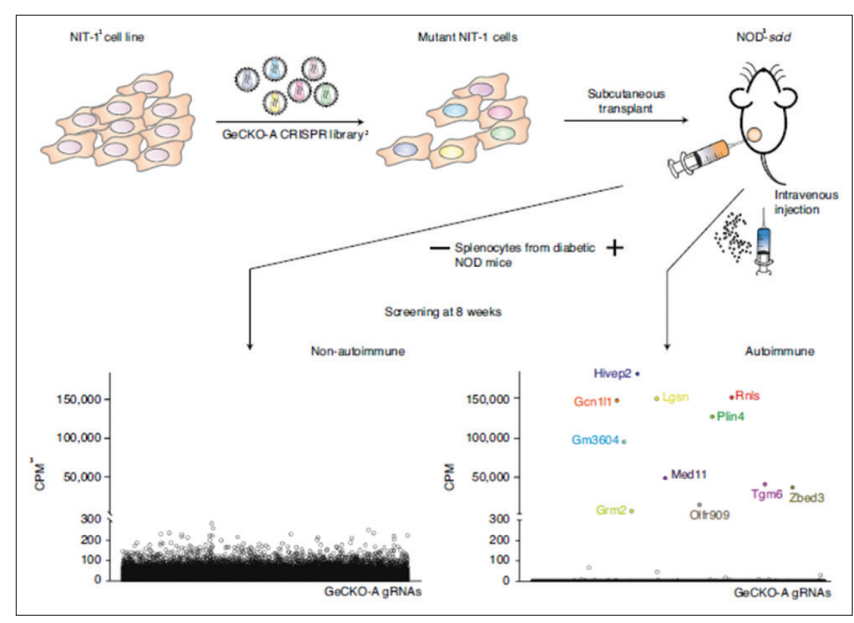

Figure 1: Using CRISPR/Cas9 to determine mutation of cell $b$ which is resistant to autoimmune reactions. NIT-1 cell ${ }^{1}$ is transduced with a collection of GeCKO2-A CRISPR lentiviral mice which were then injected subcutaneously into NOD-SCID mice with and without intravenous injection of splenocytes from diabetic NOD mice. After 8 weeks, NIT-1 grafts were taken from mice with autoimmunity (with splenocyte injection) and mice without autoimmunity (without splenocyte injection). The result found that only 11 gRNAs were detected in large numbers in mice with $b$ cell automation, one of which was RNLS gRNA [3], [27]

Based on the results of the study, the deletion of RNLS can also cause b cells to be resistant to ER stress. The study was conducted by giving TG to mice with RNLS mutation resulted in mice with mutations RNLS which is resistant to apoptosis effect caused by inflammatory cytokine IL-1b and interferon-g [27].

A similar study also showed that the deletion of the RNLS gene reduced the activation of IRE $1 \alpha$, PERK, ATF6, Elf2 $\alpha$, ATF4, and XBP1. CHOP and Txnip which function to induce apoptosis in cells were also reduced. This is due to the increased threshold which triggers the activation of the UPR. Cells $b$ with RNLS deletion were also more resistant to oxidative stress. Therefore, RNLS mutations not only protect against ER stress but also against cellular stress [27]. 


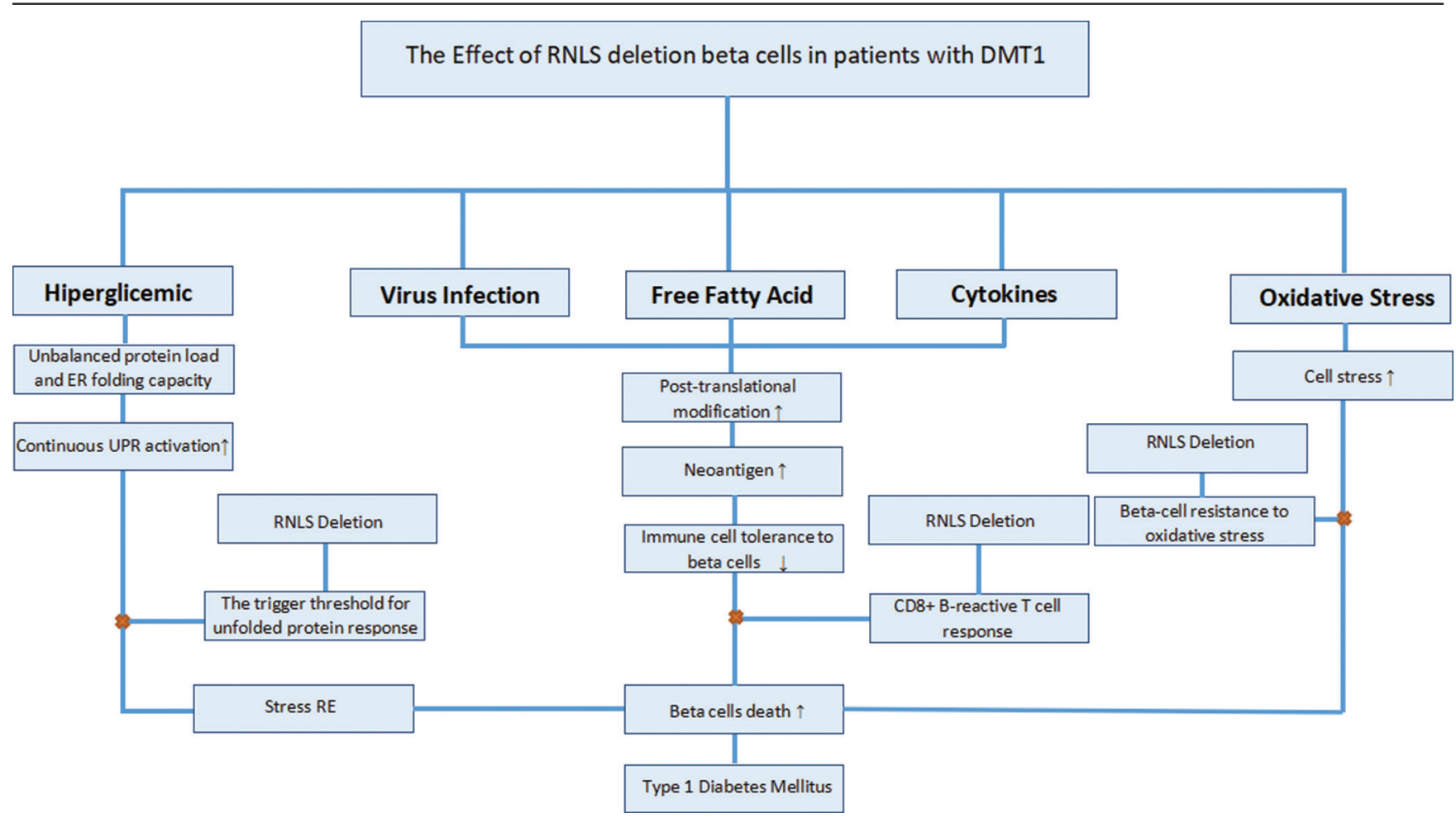

Figure 2: The framework of the deletion RNLS in preventing the death of cell $b$

Potential of pargyline as an RNLS inhibitor

Pargyline is a drug that has been approved by the Food and Drug Administration of the United States which has the same effect as the removal of RNLS on $\beta$ cells. These drugs may protect endogenous cells $\beta$ or autoimmune-transplanted cell $\beta$ from ER stress [27].

\section{Genome editing technology as a method for deleting RNLS in cell $b$}

In addition to using drugs, the deletion of RNLS can also be done by genome editing methods [27]. In 2010, genome editing methods have been applied universally, such as Zinger-Finger Nucleases, meganucleases, and transcription activator-like effector nucleases. In 2013, a study found that clustered regularly interspaced short palindromic repeatsCRISPR-related (CRISPR/Cas9) derived from the bacterial species Streptococcus pyogenes has been shown to cleave target gene sequences and allow new avenues for gene modification in mammals [34].

CRISPR-Cas is an adaptive immune system found in bacteria and archaea. This technology is a third-generation artificial nuclease technology based on the CRISPR-Cas system and is believed to be a powerful gene-editing tool [35].

Genome editing using CRISPR/Cas9 has several advantages, in which the process is simpler, faster, and cheaper than another gene editing. Nuclease engineering is efficient in a wide variety of organisms, including mammals. Therefore, there will be a significant possibility of using genome editing tools for developing cell-based human therapies that can provide life-saving therapy for various diseases such as human immunodeficiency virus infection, sickle cell anemia, and cancer. In addition, CRISPR/ Cas9 technology can also correct mutations and prevent transmission of genetic diseases from parents to offspring. Studies using human trinuclear zygotes concluded that CRISPR/Cas9 can effectively correct a mutated human-globin gene, a gene that encodes a subunit of adult hemoglobin [18], [34], [36], [37].

Although this technology has many advantages in disease prevention strategies, CRISPR/Cas9 is also still being debated, one of which is in terms of the code of ethics. In addition, the concern of off-target mutagenesis and mosaicism in the resulting animals could be a drawback of this technology [34], [36].

\section{Conclusion}

T1DM is a chronic disease in children that has a fairly high incidence and often becomes a global problem. This disease is characterized by impaired insulin production due to damage to pancreatic cells a and $b$. Insulin injection is currently a lifelong therapy for people with T1DM.

The deletion of RNLS using the CRISPR/Cas9 genome editing method can be a promising solution as a current therapy for T1DM. Apart from being faster, cheaper, and highly effective, this therapy is also 
believed to have great potential to provide therapy with a permanent effect.

It is expected that further research will be carried out to determine the effectiveness of RNLS removal therapy with the CRISPR/Cas9 method which was clinically tested to determine the side effects that can be caused by its use. So that later this therapy can be used as the main therapy for people with T1DM (Figure 2).

\section{References}

1. UKK Endokrinologi Ikatan Dokter Anak Indonesia. In: Yati NP Tridjaja B, editors. Diagnosis dan Tata Laksana Diabetes Mellitus Tipe-1 Pada Anak dan Remaja. Jakarta: Ikatan Dokter Anak Indonesia; 2017.

2. Moini J. In: Moini JB, editor. Type 1 Diabetes. Ch. 6. Amsterdam, Netherlands: Elsevier; 2019. p. 75-90.

3. Ispriantari A, Priasmoro DP. Self-acceptance in teenagers with Type 1 diabetes in Malang. Dunia Keperawatan J Keperawatan dan Kesehat. 2017;5(2):115-20.

4. Simatupang R. The Influence of Health Education Through Media Leaflets On Dm Diet On Patient Knowledge Dm At Pandan Hospital central Tapanuli Regency in 2017. IIm Kohesi. 2017;1(2):163-74.

5. Lindbladh I, Svärd AA, Lernmark $\AA$. Autoimmune (Type 1) diabetes. In: The Autoimmune Diseases. Amsterdam, Netherlands: Elsevier; 2019. p. 769-87.

6. Toniolo A, Cassani G, Puggioni A, Rossi A, Colombo A, Onodera $\mathrm{T}$, et al. The diabetes pandemic and associated infections: Suggestions for clinical microbiology. Rev Med Microbiol 2019;30:1-17.

7. Pulungan AB,Annisa D, Type 1 Diabetes Mellitus in Children: Situation in Indonesia and Management. Sari Pediatr.2019;20(6):392.

8. Afdal A, Rini EA. Neglected-noncompliant Type 1 diabetes mellitus with complications. J Kesehat Andalas. 2012;1(2):61. https://doi.org/10.25077/jka.v1i2.61

9. Warshauer JT, Bluestone JA, Anderson MS. New frontiers in the treatment of Type 1 diabetes. Cell Metab. 2020;31(1):46-61. https://doi.org/10.1016/j.cmet.2019.11.017

PMid:31839487

10. Firdausi AZ, Sriyono S, Asmoro CP. Hubungan Dukungan Keluarga dengan Kepatuhan Melakukan Latihan Fisik dan Terapi Insulin Pada Pasien Dlabetes Melitus Tipe 1 di Poliklinik Penyakit Dalam RSUD Dr. Abdoer Rahem Situbondo. Crit Med Surg Nurs J. 2016;4(2):12396

11. DiMeglio LA, Evans-Molina C, Oram RA. Type 1 diabetes. Lancet. 2018;391(10138):2449-62. https://doi.org/10.1016/ S0140-6736(18)31320-5 PMid:29916386

12. Reliance R. Kepatuhan Pasien Diabetes Melitus Dalam Menjalani Terapi Insulin di RSUPH. Adam Malik Medan; 2018.

13. Kroger CJ, Clark M, Ke Q, Tisch RM. Therapies to suppress $\beta$ cell autoimmunity in Type 1 diabetes. Front Immunol. 2018;9:1891. https://doi.org/10.3389/fimmu.2018.01891 PMid:30166987

14. Haller MJ, Gitelman SE, Gottlieb PA, Michels AW, Perry DJ, Schultz AR, et al. Antithymocyte globulin plus G-CSF combination therapy leads to sustained immunomodulatory and metabolic effects in a subset of responders with established
Type 1 diabetes. Diabetes. 2016;65(12):3765-75. https://doi. org/10.2337/db16-0823

PMid:27669730

15. Malmegrim KC, de Azevedo JT, Arruda LC, Abreu JR, Couri CE, de Oliveira GL, et al. Immunological balance is associated with clinical outcome after autologous hematopoietic stem cell transplantation in type 1 diabetes. Front Immunol. 2017;8:167. 10.3389/fimmu.2017.00167

PMid:28275376

16. Jacobsen LM, Newby BN, Perry DJ, Posgai AL, Haller MJ, Brusko TM. Immune mechanisms and pathways targeted in Type 1 diabetes. Curr Diab Rep. 2018;18(10):90. https://doi. org/10.1007/s11892-018-1066-5 PMid:30168021

17. Smail HO. The role of gene therapy in the treatments of Type 1 diabetes mellitus: A review. Biol Med Nat Prod Chem. 2020;9(2):57-64.

18. Bannikov AV, Lavrov AV. CRISPR/CAS9, the king of genome editing tools. Mol Biol (Mosk). 2017;51(4):582-94. https://doi. org/10.7868/S0026898417040036 PMid:28900076

19. Widyastuti DA. Gene Therapy: From Biotechnology to Health. Al-Kauniyah J Biol.2017;10(1):59-72.

20. Clark AL, Urano F. Endoplasmic reticulum stress in beta cells and autoimmune diabetes. Curr Opin Immunol. 2016;43:60-6. https://doi.org/10.1016/j.coi.2016.09.006

PMid:27718448

21. Marré ML, Profozich JL, Coneybeer JT, Geng X, Bertera S, Ford MJ, et al. Inherent ER stress in pancreatic islet $\beta$ cells causes self-recognition by autoreactive $T$ cells in Type 1 diabetes. J Autoimmun. 2016;72:33-46. https://doi.org/10.1016/j. jaut.2016.04.009

PMid:27173406

22. Almanza A, Carlesso A, Chintha C, Creedican S, Doultsinos D Leuzzi $\mathrm{B}$, et al. Endoplasmic reticulum stress signalling from basic mechanisms to clinical applications. FEBS $\mathrm{J}$. 2019;286(2):241-78. https://doi.org/10.1111/febs.14608 PMid:30027602

23. Cao ZH, Wu Z, Hu C, Zhang M, Wang WZ, Hu XB. Endoplasmic reticulum stress and destruction of pancreatic $\beta$ cells in Type 1 diabetes. Chin Med J 2020;133:68-73. https://doi.org/10.1097/ CM9.0000000000000583 PMid:31923106

24. Di Conza G, Ho PC. ER stress responses: An emerging modulator for innate immunity. Cells. 2020;9(3):695. https://doi. org/10.3390/cells9030695 PMid:32178254

25. Fatani TH. EIF2AK3 novel mutation in a child with early-onset diabetes mellitus, a case report. BMC Pediatr. 2019;19(1):85. https://doi.org/10.1186/s12887-019-1432-8 PMid:30922274

26. Raffel LJ, Goodarzi MO. Diabetes mellitus. Ref Modul Biomed Sci. 2014;4.

27. Cai EP, Ishikawa Y, Zhang W, Leite NC, Li J, Hou S, et al. Genome-scale in vivo CRISPR screen identifies RNLS as a target for beta cell protection in Type 1 diabetes. Nat Metab. 2020;2(9):934-45. https://doi.org/10.1038/s42255-020-0254-1 PMid:32719542

28. Li X, Huang R, Xie Z, Lin M, Liang Z, Yang Y, et al. Renalase, a new secretory enzyme: Its role in hypertensive-ischemic cardiovascular diseases. Med Sci Monit. 2014;20:688-92. https://doi.org/10.12659/MSM.890261 PMid:24762661

29. Desir GV, Peixoto AJ. Renalase in hypertension and kidney 
disease. Nephrol Dial Transplant. 2014; 29(1):22-8. https://doi. org/10.1093/ndt/gft083

PMid:24137013

30. Lv YB, Wang Y, Ma WG, Yan DY, Zheng WL, Chu C, et al. Association of renalase SNPs rs2296545 and rs2576178 with the risk of hypertension: A meta-analysis. PLoS One. 2016;11(7):e0158880. https://doi.org/10.1371/journal. pone. 0158880

PMid:27434211

31. Kolodecik TR, Reed AM, Date K, Shugrue CA, Patel V, Chung SL, et al. The serum protein renalase reduces injury in experimental Pancreatitis. J Biol Chem. 2017;292(51):2104759. https://doi.org/10.1074/jbc.M117.789776 PMid:29042438

32. Zhang T, Gu J, Guo J, Chen K, Li H, Wang J. Renalase attenuates mouse fatty liver ischemia/reperfusion injury through mitigating oxidative stress and mitochondrial damage via activating SIRT1. Oxid Med Cell Longev. 2019;2019:7534285. https://doi.org/10.1155/2019/7534285

33. Fava C, Montagnana M, Danese E, Sjögren M, Almgren $P$, Engström G, et al. The Renalase Asp37Glu polymorphism is not associated with hypertension and cardiovascular events in an urban-based prospective cohort: The Malmö Diet and cancer study. BMC Med Genet. 2012;13:57. http://doi. org/10.1186/1471-2350-13-57

PMid:22812913

34. Ormond KE, Mortlock DP, Scholes DT, Bombard Y, Brody LC, Faucett WA, et al. Human germline genome editing. Am J Hum Genet. 2017;101(2):167-76. http://doi.org/10.1016/j. ajhg.2017.06.012

PMid:28777929

35. Lu J, Liu J, Guo Y, Zhang Y, Xu Y, Wang X. CRISPR-Cas9: A method for establishing rat models of drug metabolism and pharmacokinetics. Acta Pharm Sin B. 2021;11(10):2973-82. http://doi.org/10.1016/j.apsb.2021.01.007 PMid:34745851

36. Isa NM, Zulkifli NA, Man S. Islamic perspectives on CRISPR/ Cas9-mediated human germline gene editing: A preliminary discussion. Sci Eng Ethics. 2020;26(1):309-23. http://doi. org/10.1007/s11948-019-00098-z

PMid:30830592

37. Hidayah N. Cluster Regulary Interspaced Short Palindromic Repeat Association 9 (CRISPR/Cas9) Teknologi Terbaru Editing Gen Human Pluripotent Stem Cells (Hpscs) Sebagai Terapi Penyakit Diabetes Mellitus Tipe 1. Vol. 8. Khazanah: Jurnal Mahasiswa; 2020. 